\title{
FREQUENCY OF UTERINE RUPTURE AFTER ONE SUCCESSFUL VAGINAL BIRTH AFTER CESAREAN SECTION (VBAC).
}

\footnotetext{
1. FCPS

Assistant Professor Obs \& Gynae Nishtar Medical University, Multan. 2. FCPS

Senior Registrar Obs \& Gynae Nishtar Medical University, Multan. 3. FCPS

Associate Professor Obs \& Gynae Nishtar Medical University, Multan. 4. MBBS

Medical Officer Obs \& Gynae Nishtar Medical University, Multan.

Correspondence Address:

Dr. Shazia Siddiq

Obs \& Gynae

Nishtar Medical University, Multan.

shaziasiddiq@yahoo.com

Article received on:

01/07/2019

Accepted for publication:

05/11/2019
}

\begin{abstract}
Shazia Siddiq ${ }^{1}$, Saima Yasmin Qadir ${ }^{2}$, Hajra Sultana ${ }^{3}$, Asma Khurshid ${ }^{4}$
ABSTRACT... Objectives: To determine the frequency of uterine rupture after one successful vaginal birth after caesarean section. Study Design: Cross Sectional Study. Setting: Department of Obstetrics and Gynecology of Nishtar Hospital Multan. Period: 12-May-2017 to 11-May-2018. Material \& Methods: Total number of 135 patients of 16-45 years with singleton pregnancies were admitted for $2^{\text {nd }}$ Vagina Birth after cesarean Section at gestational age $\geq 28$ weeks of gestation. Data in shape of parity, gestational age and BMI was taken. These patients were assessed for frequency of uterine rupture after one successful vaginal birth after caesarean section. Data was analyzed with statistical analysis program (SPSS version 21). Frequency and percentage was calculated for qualitative variables like parity and uterine rupture. Mean \pm SD was calculated for quantitative variables like age, BMI and gestational age. Results: Mean age of patients was $29.88 \pm 5.34$ years. Mean body mass index (BMI) of study patients was $25.17 \pm 4.88 \mathrm{~kg} / \mathrm{m}^{2}$. Mean gestational age at the time of delivery was $39.01 \pm 2.54$ weeks. Uterine rupture after vaginal birth occurred in $2(1.48 \%)$ patients. There was no association of gestational age, parity and gestational age with the frequency of uterine rupture. Conclusion: Women with prior successful VBAC are at low risk of maternal and neonatal complications during subsequent trail of VBAC with lower risk of uterine rupture and perinatal complications.
\end{abstract}

Key words: $\quad$ Cesarean Section, Labor, Perinatal Complications, Safety, Uterine Rupture, Vaginal Birth after Cesarean Section.

Article Citation: Siddiq S, Qadir SY, Sultana H, Khurshid A. Frequency of uterine rupture after one successful vaginal birth after cesarean section (VBAC). Professional Med J 2020; 27(4):807-811. DOI: 10.29309/TPMJ/2020.27.04.3885

\section{INTRODUCTION}

In modren obstetrics, it is now routine practice to give trial of vaginal birth after one cesarean section, also called as trail of scar. The probability of a successful vaginal birth has been estimated about $70-80 \% .^{1}$ Although VBAC is considered safe with good monitoring but it is not without complications like increased risk of uterine rupture, which is no doubt a life threatening emergency. The incidence of uterine rupture in a spontaneous labor after one prior lower transverse segment caesarean section is $0.4 \% .^{2}$ Mercer has reported its frequency by $0.45 .{ }^{3}$ Gyamfi reported $0.5 \% .{ }^{4}$ There is increased risk of operative injury like peripartum hysterectomy and fetal death. Unsuccessful trial ending up in cesarean section results in increased perioperative morbidity.

Now a days the frequency of cesarean section is enormously high and most of the caesarean section are performed for non-recurrent indications. So many women undergo successful vaginal delivery rather repeat cesarean section. ${ }^{3}$ The effect of caesarean scar strength on uterine rupture during vaginal birth remains unclear. It is not clearly known that repeated vaginal birth following cesarean section increases the risk of uterine rupture because of progressive weakening of the scar with each birth or successive deliveries may improve the strength of the scar and predict successful vaginal deliveries. ${ }^{5}$

The probability of uterine rupture in successive VBACs remains to be clearly explained. It is should be emphasized either successive labors will have progressive thinning of uterine scar resulting in uterine rupture. From this study we may find group of patients with uterine rupture to identify those patients in whom further interventions and follow up can be planned. This gives strong 
rational to see frequency of uterine rupture after one successful vaginal birth after caesarean section in our population. This study may also provide background data for curative services to prevent uterine rupture after caesarean section after one successful vaginal birth.

\section{MATERIAL AND METHODOLOGY}

After permission from hospital ethical committee, cross sectional study was performed on one hundred and thirty five patients fulfilling inclusion criteria of gestational age more than 28 weeks, history of previous one successful VBAC. The patients with uterine surgery other than cesarean section, twin pregnancy and classical cesarean scar were excluded. The sample was taken by non-probability consecutive sampling technique. An informed consent was obtained from all patients for using their clinical data in research. Patients were evaluated by detailed history and clinical examination. Data in age, shape of parity, gestational age and BMI was gathered. These patients were assessed for frequency of uterine rupture after one successful vaginal birth after caesarean section, which was performed by year four resident of gynecology and obstetrics.

Statistical package for social sciences (SPSS version 21) was used for analyzing the patient's data. Frequency and percentage were calculated for qualitative variables like parity and uterine rupture. Mean \pm SD was calculated for quantitative variables like age, BMl and gestational age.

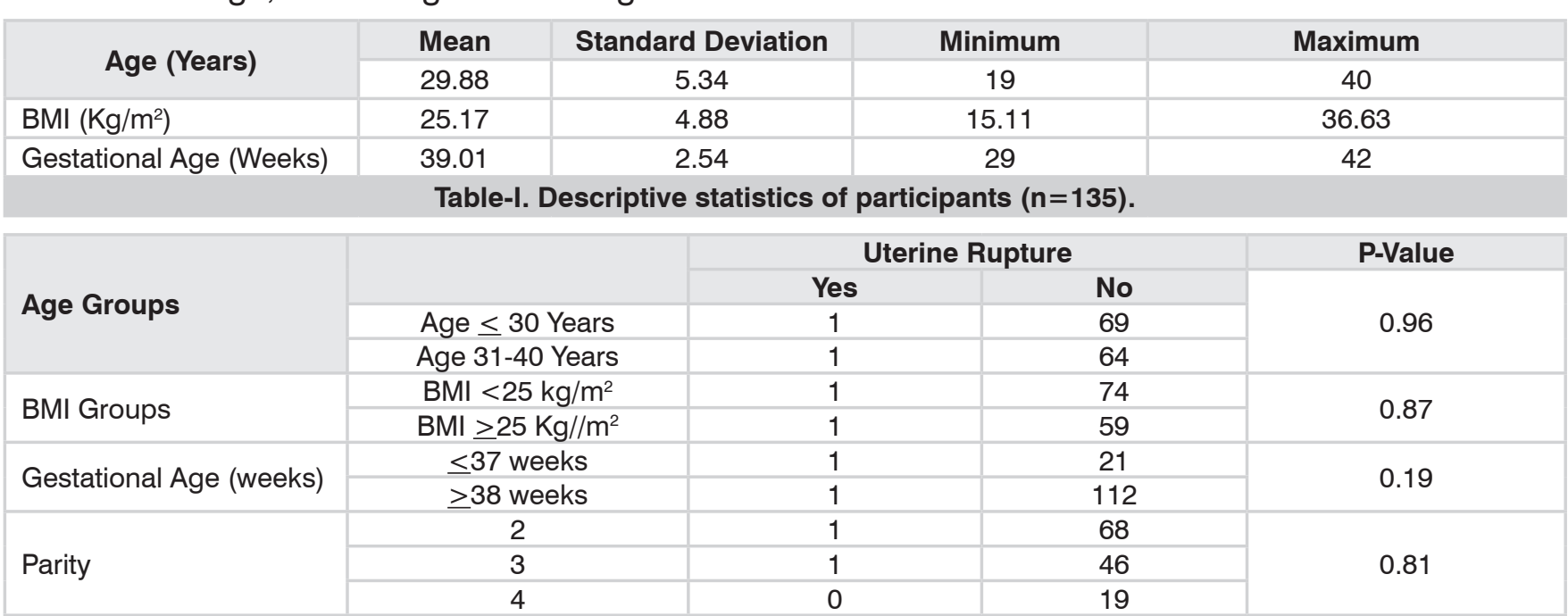

Table-II. Stratification of frequency of Uterine Rupture with age, BMI, gestational age, and parity $(n=135)$
Stratification was done for age, parity, gestational age and BMI to observe the effect of these variables on outcome. Chi-square test was applied, $\mathrm{p} \leq 0.05$ was considered significant.

\section{RESULTS}

Table-I showed that mean age of $29.88+5.34$ years with range of 19 to 40 years among all was $25.17+4.88 \mathrm{~kg} / \mathrm{m}^{2}$ with minimum $\mathrm{BMl}$ of $15.11 \mathrm{Kg} / \mathrm{m}^{2}$, while maximum BMI of $36.63 \mathrm{Kg} / \mathrm{m}^{2}$. Mean gestational age at the time of delivery was $39.01+2.54$ weeks with minimum gestational age of 29 weeks, while maximum gestational age of 42 weeks.

Figure-1 presented the parity status, there were $69(51.11 \%)$ pregnant females having parity status 2, 47 (34.82\%) were having parity status 3 status 4.

Uterine rupture after vaginal birth occurred in $\mathrm{n}=2$ $(1.48 \%)$ patients in our study. While in remaining $133(98.52 \%)$ patients there was no incidence of uterine rupture (Figure-2).

Table-Il showed the relationship with age, BMI, gestational age and parity with the frequency of uterine rupture. There was no significant relationship with any of these variables with the rupture of uterus $(p=>0.05)$ patients. Mean body mass index (BMI) of patients and only 19 (14.07\%) females were having parity 


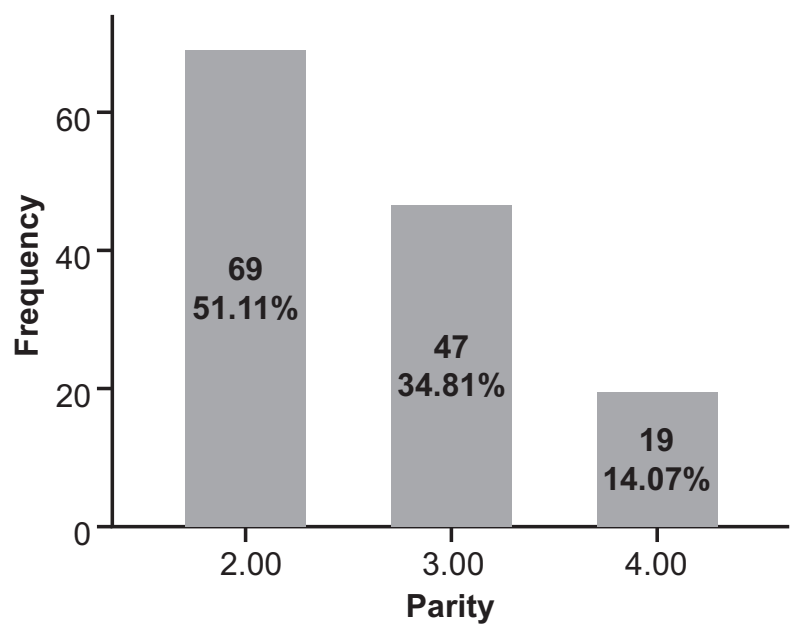

Figure-1. Frequency of parity status of patients $(n=135)$.

\section{DISCUSSION}

Uterine rupture is a serious obstetrical emergency associated with potentially life threatening complications both for mother and fetus. ${ }^{6}$ Incidence of cesarean section has increased enormously in developing countries, so the risk of uterine rupture after prior cesarean section. According to World Health Organization (WHO), the frequency of uterine rupture is more common in developing countries than in developed countries. ${ }^{7}$ Uterine rupture after prior cesarean section is becoming more common because of quick and easy availability of cesarean section as a primary surgical procedure in developing countries. The major risk factors of uterine rupture are associated with prior cesarean section followed by unsupervised vaginal birth trail, obstructed labor, grand multiparity, obstetric interventions, induction at unripe cervix ${ }^{8}$, poor access to emergency obstetric care and high prevalence of illiteracy and poverty.

In our study, the frequency of uterine rupture in patients during trial of vaginal birth with one successful VBAC was $1.48 \%$. Berhe and Shirivastava reported the high prevalence of uterine rupture in developing countries, the proportion of women with prior cesarean section to uterine rupture was up to $64 \% .^{9,10}$ Shirivastava observed the incidence of uterine rupture among women with prior cesarean section was $1.69 \%$ and frequency of uterine rupture without prior

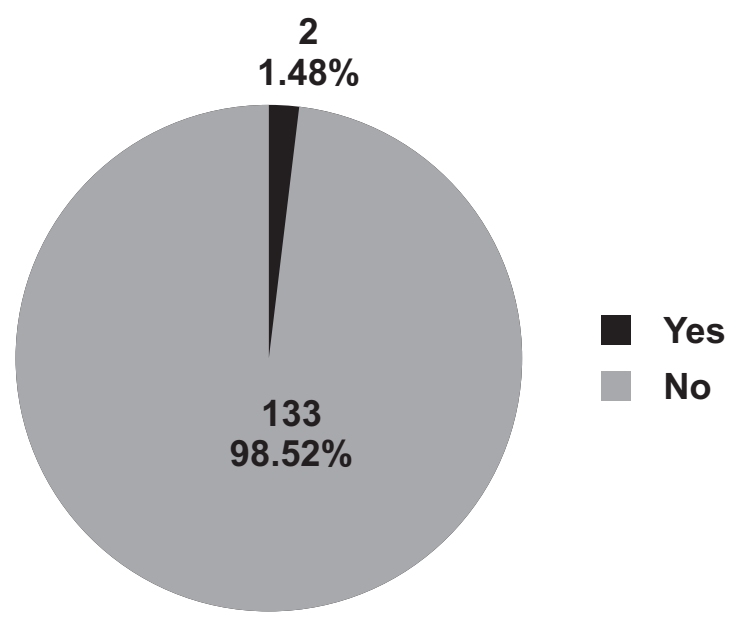

Figure-2. Frequency of uterine rupture $(n=135)$

cesarean section was $0.152 \% .{ }^{10}$ Al-Zirqi and Jastrow observed the frequency of uterine rupture in women with prior CS from range from $0.22 \%$ to $1.69 \% .^{11,12}$ Vaarasmaki reported about rupture as the most feared complication with the occurrence of $0.2-1.5 \% .{ }^{13}$ The frequency of uterine rupture is $1.0 \%$ in low human development index countries according to recently published multicentericstudy from World Health Organization by Motomora. He concluded that the incidence of uterine rupture varied globally, ranging from $0.1 \%$ to $2.5 \% .{ }^{14}$ he added that risk of uterine rupture was associated with early gestational age along with poverty and low education level of communities. He observed a significant relationship between gestational age at birth less than 37 weeks and uterine rupture. ${ }^{14}$ kacmarczyk observed that higher gestational age is usually associated with uterine rupture. ${ }^{15}$ Harper compared uterine rupture with gestational age before or after 34 weeks of gestation and found no difference. ${ }^{16}$ In our study, we did not find any significant difference in frequency of uterine rupture in patients with gestational age before or after 37 weeks. In our study, frequency of uterine rupture was not associate with increased BMI, while Wilson observed that women with a BMI over 40 had lower rates of successful VBAC but no difference in uterine rupture. ${ }^{17}$

\section{CONCLUSION}

Prior successful VBAC is strong predictor of subsequent successful trail of VBAC with low risk 
of maternal and neonatal complications.

\section{RECOMMENDATION}

Risk of subsequent uterine rupture can be reduced by limiting the primary cesarean sections in low resource settings and steps must be taken by health care department and all the stakeholders to devise strict decisions regarding indications of cesarean sections.

\section{Copyright@ 05 Nov, 2019.}

\section{REFERENCES}

1. Tessmer-Tuck JA, EL-Nashar SA, Racek AR, Lohse CM , Famuyide AO, Wick MJ. Predicting vagnal birth after cesarean section: A cohort study. Gynecol Obstat Invest. 2014; 77(2): 121-6.

2. London MB, Hauth JC, Leveno KJ. Maternal and perinatal outcomes associated with a trial of labor after a prior caesarean delivery. $\mathrm{N}$ England $\mathrm{J}$ Med. 2014; $351(25):$ 2581-9.

3. Mercer BM, Gilbert S, London MB, Spong CY. Labor outcomes with increasing number of prior vaginal birth after caesarean delivery. Am J Obstet Gynecol. 2008; $111(2): 285-91$.

4. Gyamfi C, Juhasz G, GymafiP, Stone JL. Increased success of trial of labor after previous vaginal birth after caesarean. Obstat Gynecol. 2004; 104(4): 715-9.

5. Shimonovits S, Botosneano A, Hochner-celnikier D. Successful first vaginal birth after caesarean section: A predictor of reduced risk for uterine rupture in subsequent deliveries. Isr Med Assoc J. 2000 Jul; 2(7): 526-8.

6. Lannon SM, Guthrie KA, Vanderhoeven JP, Gammll HS. Uterine rupture risk after periviable Caesarean delivery. Obstete Gynecol. 2015; 125 (5): 1095-100. Eden RD, Parker RT, Gall SA. Rupture of the pregnant uterus: A 53year review. Obstet Gynecol. 1986; 68 (3):671-4.

7. Justus Hofmeyr G, Say L, Metin Gülmezoglu A. Systematic review: WHO systematic review of maternal mortality and morbidity: The prevalence of uterine rupture. BJOG. 2005; 112(9):1221-8.
8. Thisted DLA, Mortensen LH, Hvidman L, Krebs L. Operative technique at caesarean delivery and risk of complete uterine rupture in a subsequent trial of labour at term. A registry case-control study. PLoS One. 2017; 12(11):e0187850.

9. Berhe $Y$, Wall LL. Uterine rupture in resource-poor countries. Obstet Gynecol Survey. 2014; 69(11):695707.

10. Singh A, Shrivastava $C$. Uterine rupture: still a harsh reality!. J Obstet Gynecol India. 2015; 65(3):158-61.

11. Al-Zirqi I, Stray $\square$ Pedersen B, Forsén L, Vangen S. Uterine rupture after previous caesarean section. BJOG. 2010; 117(7):809-20.

12. Jastrow N, Vikhareva O, Gauthier RJ, Irion O, Boulvain $\mathrm{M}$, Bujold $\mathrm{E}$. Can third $\square$ trimester assessment of uterine scar in women with prior Cesarean predict uterine rupture?. Ultrasound Obstet Gynecol. 2016; 47(4):410-4.

13. Vääräsmäki M, Raudaskoski T. Pregnancy and delivery after a cesarean section. Duodecim. 2017; 133(4): 345-52.

14. Motomura K, Ganchimeg T, Nagata C, Ota E, Vogel JP, Betran AP, et al. Incidence and outcomes of uterine rupture among women with prior caesarean section: WHO Multicounty Survey on Maternal and Newborn Health. Sci Report. 2017; 7:44093.

15. Kaczmarczyk M, Sparén $P$, Terry $P$, Cnattingius $S$. Risk factors for uterine rupture and neonatal consequences of uterine rupture: A population $\square$ based study of successive pregnancies in Sweden. BJOG. 2007; 114(10):1208-14.

16. Harper LM, Cahill AG, Stamilio DM, Odibo AO, Peipert JF, Macones GA. Effect of gestational age at the prior cesarean delivery on maternal morbidity in subsequent VBAC attempt. Am J Obstet Gynecol. 2009; 200(3):276 e1-6.

17. Wilson E, Sivanesan K, Veerasingham M. Rates of vaginal birth after caesarean section: What chance do obese women have? Aust N Z J Obstet Gynaecol. 2019; 18. doi: 10.1111.13003. 


\begin{tabular}{|c|c|c|c|}
\hline \multicolumn{4}{|c|}{ AUTHORSHIP AND CONTRIBUTION DECLARATION } \\
\hline Sr. \# & Author(s) Full Name & Contribution to the paper & Author(s) Signature \\
\hline 1 & Shazia Siddiq & $\begin{array}{l}\text { Data collection and analysis, } \\
\text { Study design, Interpretation, } \\
\text { Pricipal Investigator, Final } \\
\text { reading. }\end{array}$ & \\
\hline 2 & Saima Yasmin Qadir & $\begin{array}{l}\text { Data collection and analysis, } \\
\text { Study design, Interpretation, } \\
\text { Pricipal Investigator, Final } \\
\text { reading. }\end{array}$ & \\
\hline 3 & Hajra Sultana & $\begin{array}{l}\text { Data collection and analysis, } \\
\text { Study design, Interpretation, } \\
\text { Pricipal Investigator, Final }\end{array}$ & ran \\
\hline 4 & Asma Khurshid & $\begin{array}{l}\text { reading. } \\
\text { Data collection and analysis, } \\
\text { Study design, Interpretation, } \\
\text { Pricipal Investigator, Final } \\
\text { reading. }\end{array}$ & \\
\hline
\end{tabular}

